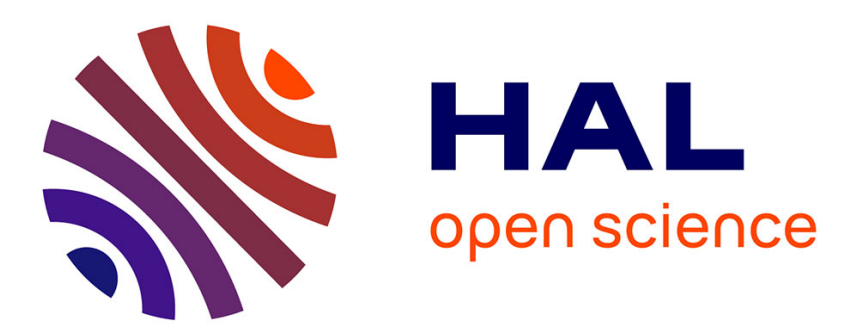

\title{
Numerical modelling of laser rapid prototyping by fusion wire deposit
}

\author{
Larbi Arbaoui, J.E. Masse, Laurent Barrallier, Katia Mocellin
}

\section{To cite this version:}

Larbi Arbaoui, J.E. Masse, Laurent Barrallier, Katia Mocellin. Numerical modelling of laser rapid prototyping by fusion wire deposit. 13th ESAFORM Conference on Material Forming, Apr 2010, Brescia, Italy. pp.Pages 1095-1098, 10.1007/s12289-010-0962-2 . hal-00614026

HAL Id: hal-00614026

https://hal-mines-paristech.archives-ouvertes.fr/hal-00614026

Submitted on 14 Aug 2013

HAL is a multi-disciplinary open access archive for the deposit and dissemination of scientific research documents, whether they are published or not. The documents may come from teaching and research institutions in France or abroad, or from public or private research centers.
L'archive ouverte pluridisciplinaire HAL, est destinée au dépôt et à la diffusion de documents scientifiques de niveau recherche, publiés ou non, émanant des établissements d'enseignement et de recherche français ou étrangers, des laboratoires publics ou privés. 


\title{
NUMERICAL MODELLING OF LASER RAPID PROTOTYPING BY FUSION WIRE DEPOSIT
}

\author{
L. Arbaoui ${ }^{\text {** }}$,J.-E. Masse ${ }^{2}$, L. Barrallier ${ }^{2}$, K. Mocellin ${ }^{1}$ \\ ${ }^{1}$ UMR CNRS 7635 CEMEF/ Mines Paristech, B.P 207, 06904 Sophia Antipolis Cedex France \\ ${ }^{2}$ Arts Et Métiers Paristech, Aix En Provence France Groupe Mécasurf
}

\begin{abstract}
A finite element model has been developed to simulate an innovative laser rapid prototyping process. Several numerical developments have been implemented in order to simulate the main steps of the rapid prototyping process: injection, heating, phase change and deposit. The numerical model also takes into account different phenomena: surface tension in the liquid state, asborptivity and plasma effects during material-laser interaction. The three-dimensional model is based on the lagrangian approach used in the Forge ${ }^{\circledR}$ finite element software. The thermal model coupled with material-laser model is compared and gives good agreements. Simulations of the rapid prototyping are compared with experimental results.
\end{abstract}

KEYWORDS: 3D finite element, lagrangian formulation, absorptivity, plasma, phase change, surface tension

\section{INTRODUCTION}

The laser rapid prototyping process by fusion wire deposit is a solid freeform fabrication method. This process uses additive part from the wire. The successive fusion wire deposit will allow building product with complex geometries. This rapid prototyping process is a new concept to create metal prototypes. The innovation comes from the deposition of a wire melted by laser during the injection of the metal wire. This rapid prototyping enables to create more complex products than the ones crated by metal powder rapid prototyping. The laser rapid prototyping by fusion wire deposit, as shown in Figure 1, is composed of:

- CO2 laser which is characterised by doughnut mode

- several mirrors to focus the laser on the metal wire

- substrate which moves on all directions

- injection tool to add the metal wire

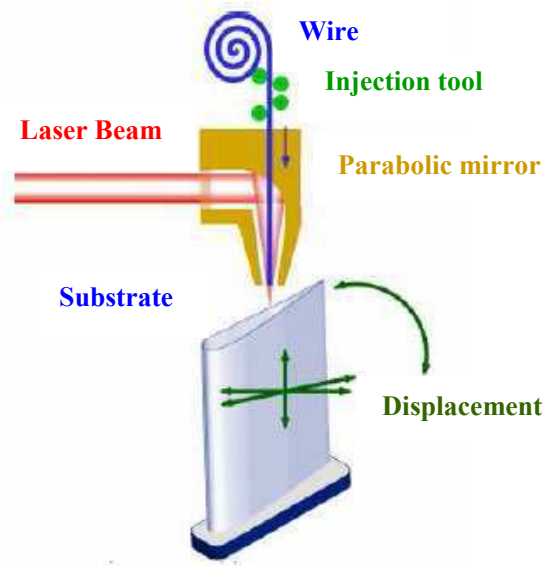

Figure 1: Schematic of laser rapid prototyping
The process takes place as follows. First, the solid metal wire is injected continuously. The wire is heated and melted during laser interaction. The melted material is then laid on the substrate. Finally, the material adheres and solidifies on the substrate by cooling.

Different phenomena are observed during the process: thermal, mechanical, metallurgical and optical effects.

Numerical developments have been carried out in order to simulate different stages and phenomena of the process; they are integrated on thermomechanical finite element model by coupling mechanical model, thermal model and material-laser interaction model.

\section{MECHANICAL MODEL}

\subsection{CONTINUITY EQUATION}

The physical model is first based on the equilibrium (1) and incompressibility (2) equations:

$$
\rho \frac{d v}{d t}=\nabla \cdot \sigma+\rho g
$$

$$
\nabla \cdot v=0
$$

Where $\sigma$ denotes the stress tensor, $v$ the velocity vector, $\rho$ the density and $g$ the gravity

\subsection{PHASE CHANGE}

The solid liquid phase change takes place in the process when the wire is melted by the laser. This phase change is modelled by a rheology transition in the numerical model as presented in Figure 2.

The constitutive law changes gradually from elasticviscoplastic $\bar{\sigma}_{e v p}$ to viscoplastic $\bar{\sigma}_{v p}$ (Non Newtonian) during heating and inversely during cooling $[1,2]$ : 


$$
\begin{gathered}
\bar{\sigma}_{v p}=K(T)(\sqrt{3})^{m(T)+1} \dot{\bar{\varepsilon}}^{m(T)} \overline{\mathcal{\varepsilon}}^{n(T)} \\
\bar{\sigma}_{e v p}=\sigma_{0}+K(T)(\sqrt{3})^{m(T)+1} \dot{\bar{\varepsilon}}^{m(T)} \overline{\mathcal{\varepsilon}}^{n(T)} \\
\sigma_{0}=\sqrt{3} K(T)
\end{gathered}
$$

where $K$ is the viscoplastic consistency, $\dot{\bar{\varepsilon}}$ is the equivalent Von Mises strain rate, $m$ is the strain rate

\begin{tabular}{|c|c|c|c|}
\hline $\begin{array}{c}\text { EVP } \\
\text { behavior }\end{array}$ & \multicolumn{2}{|c|}{$\begin{array}{c}\text { VP } \\
\text { behavior }\end{array}$} & $\begin{array}{c}\text { Newtonian } \\
\text { behavior }\end{array}$ \\
\hline Solid state & \multicolumn{2}{|c|}{ Mushy state } & Liquid state \\
\hline \multicolumn{2}{|c|}{$\begin{array}{c}\text { Solidus } \\
\text { temperature }\end{array}$} & \multicolumn{2}{|c|}{$\begin{array}{c}\text { Liquidus } \\
\text { temperature }\end{array}$} \\
\hline
\end{tabular}
sensitivity, $\bar{\varepsilon}$ is the equivalent von Mises strain, $n$ is the strain hardening coefficient and $\sigma_{0}$ is the yield stress.

\section{Figure 2: Phase change model}

The change takes place according to criteria (6) and (7) based on the averaged temperature on mesh element $\bar{T}_{\text {elt }}$ :

$$
\left\{\begin{array}{l}
\bar{T}_{\text {elt }}<T_{\text {solidus }} \Rightarrow \bar{\sigma}_{\text {evp }} \\
\bar{T}_{\text {elt }} \geq T_{\text {solidus }} \Rightarrow \bar{\sigma}_{v p}
\end{array}\right.
$$

For the liquid state, a Newtonian behaviour is considered:

$$
\bar{T}_{\text {elt }}>T_{\text {liquidus }} \Rightarrow \bar{\sigma}_{\text {newtonian }}=3 K(T) \dot{\bar{\varepsilon}}
$$

\subsection{NUMERICAL INJECTION}

To avoid an important computation time and cost in memory, the input of the wire is modelled by a continuous inflow of material.

The injection is done on a section of the wire. Both experimentally and numerically, the injection condition is located far enough from the phase change and the critical heating effect. The volume of the part increases, but during calculation at any time step, the volume is kept constant to comply with the hypothesis of incompressibility [3].

In lagrangian formulation, the point coordinates $x$ of mesh are moved with eulerian actualisation:

$$
x^{t+\Delta t}=x^{t}+v \Delta t
$$

A velocity value is prescribed for all points of the section where the wire is injected; this value of speed is a process parameter. The displacement is then the same for the points localised before the section. For each time step, all points locations are actualised with the calculated velocity, except for points located on the injection section.

$$
\left\{v_{\text {injection }}=v_{\text {process }} ; v_{\text {mesh }}=0 \quad \tau_{\text {injection }}\right\}
$$

\subsection{SURFACE TENSION}

In the rapid prototyping process, the wire is laid on the metal substrate at liquid state. The effect of surface tension appears during the liquid state and drives the shape of the deposit on the substrate.

The numerical model takes into account the surface tension in the lagrangian formulation. The surface tension is a normal stress to the liquid surface, and following pressure condition must be satisfied:

$$
P=\kappa \gamma
$$

where $\kappa$ is the free surface curvature and $\gamma$ is the surface tension coefficient.

In a weak formulation, the Laplace-Beltrami operator is used to estimate the curvature [4]:

$$
\stackrel{\Delta \vec{x}}{=} \kappa \vec{n}
$$

And the tangential gradient is expressed to formulate the weak formulation of the mechanical problem [5]:

$$
\underline{\nabla} f(x)=\nabla f(x)-(\vec{n} \cdot \nabla f(x)) \vec{n}
$$

So the weak formulation on the free surface $\Gamma$ and on triple line $\partial \Gamma$ is:

$$
\int_{\Gamma} \gamma \hat{\kappa} \vec{n} \cdot v^{*} d \Gamma=-\int_{\Gamma} \gamma \underline{\nabla} \vec{x} \cdot \underline{\nabla} v^{*} d \Gamma+\int_{\partial \Gamma} \gamma \partial \gamma \vec{x} \cdot v^{*} d(\partial \Gamma)
$$

For points located on the triple line, the effect of wetting angle $\theta$ is modelled as follow:

$$
\int_{\partial \Gamma} \gamma \partial \gamma \vec{\gamma} \cdot w d(\partial \Gamma)=\int_{\partial \Gamma} \gamma \cos (\theta)\left(w \cdot \tau_{\gamma}\right) d(\partial \Gamma)
$$

\section{THERMAL MODEL}

In the rapid prototyping process, the laser beam energy is absorbed on the surface and heat is conducted into the material. The power density of the laser beam makes the melting and vaporisation of the metal possible.

\subsection{HEATING}

The heat conduction equation is coupled with the mechanical equations. The dissipated power is taken as source term of the heat conduction equation:

$$
\rho c_{p} \frac{\partial T}{\partial t}-\nabla(k \nabla T)=\sigma: \dot{\varepsilon}
$$

Convection of melted material is neglected due to the minimal thickness of the liquid layer. The heat flux is the heat source created by the laser beam:

$$
-k \frac{\partial T}{\partial \vec{n}}=q_{\text {laser }}+q_{\text {rad }}
$$

As mentioned for the mechanical model, parameters as conductivity $k$ and specific heat capacity $c_{p}$ depend on temperature. 


\subsection{MELTING}

The melting phase transition can be approximated by considering the heat loss of melting through a change in the specific heat. Enthalpy method is used for latent heat. The modification of the specific heat capacity is expressed with the liquid mass fraction $f_{L}$ and the latent heat of fusion $H_{L}$ :

$$
c_{p}^{*}=c_{p}+H_{L} \frac{d f_{L}(T)}{T}
$$

The liquid mass fraction can be approximated by:

$$
f_{L}(T)=\frac{T-T_{\text {solidus }}}{T_{\text {liquidus }}-T_{\text {solidus }}}
$$

\subsection{VAPORIZATION}

The vaporisation can be estimated by the energy losses induced by vaporised material. The energy losses by vaporisation can be included in the boundary condition defined by the surface flux of heat:

$$
k \frac{\partial T}{\partial \vec{n}}=q_{\text {laser }}+q_{\text {rad }}-q_{\text {vap }}
$$

The vaporisation is modelled by heat losses on the surface irradiated by the laser. The model describes the relation between surface temperature and latent heat of vaporization [6]:

$$
\begin{gathered}
q_{\text {vap }}=W H_{V} \\
\log (W)=A_{v}+\left(6.121-\frac{18836}{T_{S}}\right)-\frac{\log \left(T_{S}\right)}{2}
\end{gathered}
$$

\section{MATERIAL-LASER INTERACTION MODEL}

The material-laser interaction model is limited to a continuous wave $\mathrm{CO} 2$ laser and a metal target. Those limitations are important because the associated wavelength $\lambda$ and the nature of the material heated by the laser generate special effects and mechanisms.

\subsection{LASER HEAT FLUX}

The main coupling between material-laser model and thermal model is the expression of the laser heat flux.

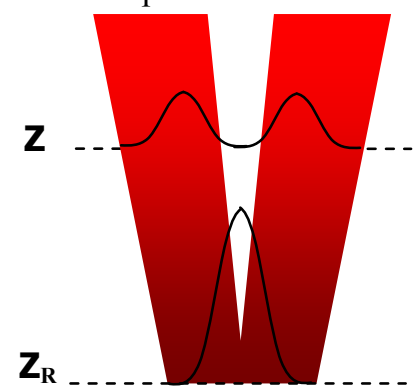

Figure 3: laser power density with distance of focal plane
The power density of the laser beam is described by a specific formulation. Indeed the $\mathrm{CO} 2$ laser is characterised by the doughnut mode. The mirror focuses the beam on the metallic substrate and the wire is injected in the centre of the beam.

The power density of the laser beam decreases when the distance to focal plane increases as shown in Figure 3.

At the focal plane level, the intensity of the laser is a Gaussian. And parameters which characterise the intensity are the power $P_{\boldsymbol{0}}$ and the radius $r_{\boldsymbol{0}}$ :

$$
I(x, y)=\frac{2 P_{0}}{\pi r_{0}{ }^{2}} \exp \left(-\frac{2\left(x^{2}+y^{2}\right)}{r_{0}^{2}}\right)
$$

Equation (22) takes into account the doughnut mode while the radius $r(z)$ at a distance to focal plane depends on the Rayleigh distance $z_{R}(23)$.

$$
\left\{\begin{array}{c}
I(x, y, z)=\frac{2 P_{0}\left(x^{2}+y^{2}\right)}{\pi r^{2}(z)} \exp \left(-2 \frac{x^{2}+y^{2}}{r^{2}(z)}\right) \\
r^{2}(z)=r_{0} \sqrt{1+\left(\frac{z}{z_{R}}\right)^{2}} ; z_{R}=\frac{\pi r_{0}^{2}}{\lambda}
\end{array}\right.
$$

\subsection{ABSORPTIVITY}

The absorptivity is a material parameter that quantifies the laser energy absorbed on the surface of the material. The absorption coefficient is neglected because of the weak penetration of the laser inside the metal. It is then acceptable to consider that the laser interacts on the surface metal target only. The absorptivity can be expressed by the Bransom model [7], which links absorpitvity $\alpha(T)$ with resistivity $r(T)$ and laser wavelength $\lambda$ :

$$
\begin{gathered}
q_{\text {laser }}=\alpha(T) I(x, y) \\
\alpha(T)=0.365\left[\frac{r(T)}{\lambda}\right]^{1 / 2}-0.0667\left[\frac{r(T)}{\lambda}\right]+0.006\left[\frac{r(T)}{\lambda}\right]^{3 / 2}
\end{gathered}
$$

\subsection{PLASMA}

At the substrate laser interaction level, vaporised material ionizes to form plasma. In the case of infrared laser beams, the dominant absorption mechanism in plasma is inverse bremsstrahlung mechanism [8].

The plasma model takes into account the mechanism of plasma absorption $\alpha_{B I}$ and the effect of irradiation due to the high temperature of the plasma.

$$
\alpha_{B I}=1,8 \cdot 10^{-35} \frac{n_{e}^{2}}{T_{e}^{3 / 2}}
$$

On the area of material-laser interaction, when the temperature of mesh point exceeds the boiling temperature, the heat flux at this point changes as follows: 


$$
\begin{gathered}
q_{\text {laser / plasma }}=\alpha(T) I(x, y)\left[1-\exp \left(-\int_{0}^{z} \alpha_{B I} d z\right)\right] \\
q_{\text {rad / plasma }}=\varepsilon \sigma\left(\bar{T}_{\text {plasma }}^{4}-T^{4}\right)
\end{gathered}
$$

\section{RESULTS}

\subsection{Thermal results}

The temperature is measured by using thermocouples located at $3 \mathrm{~mm}$ of the surface of the laser heated plate. Laser powers of $300 \mathrm{~W}$ and $2500 \mathrm{~W}$ have been used. The plate is placed at focal plane. Two levels of modelling are studied, considering the presence or not of plasma during laser impact. The first curve in Figure 4, shows the pertinence of the thermal model coupled for lowers intensities. An evaluation of absorptivity for temperatures greater than fusion temperature has been necessary because the limitation of the Bransom model (25) to solid state. For the second curve in Figure 4, parameters of the plasma model described in $(26,27$ and 28) have been estimated. in order to give the best correlation.
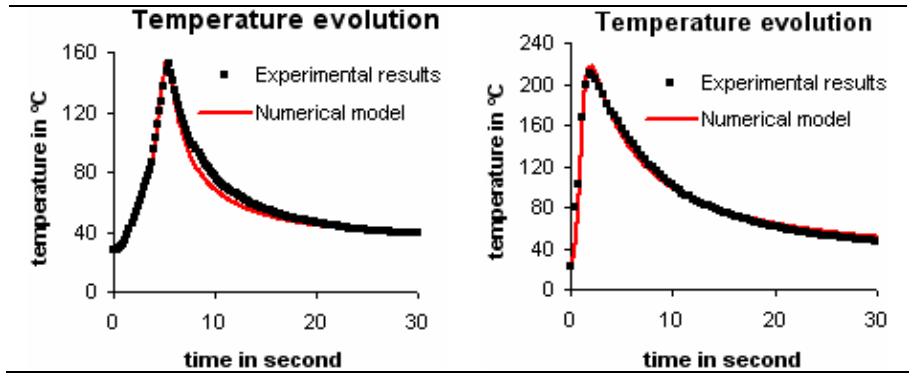

Figure 4: Comparison of thermal results

\subsection{First simulation of process}

The simulation of this laser rapid prototyping can predict a critical phenomenon which appears in the experimental process: the drop formation as shown in Figure 5.

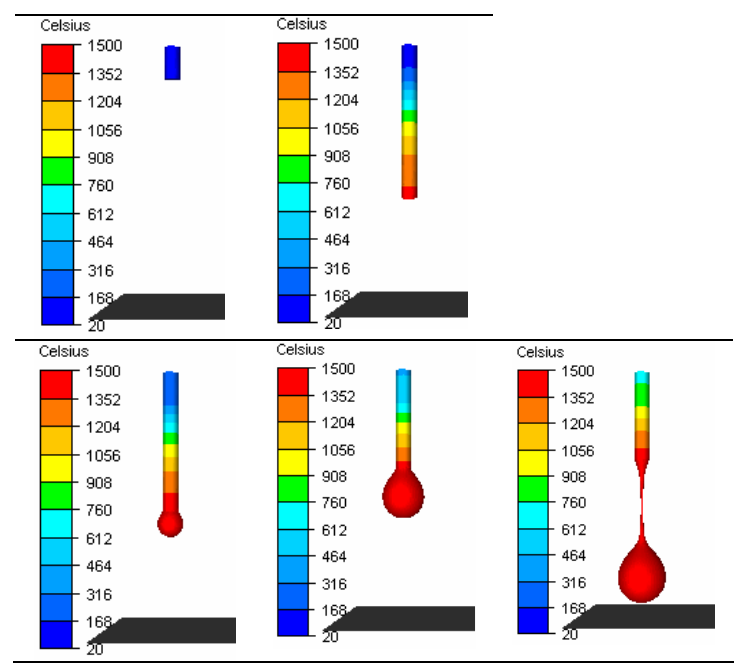

Figure 5: Simulation of drop formation
The thermomechanical model coupled with materiallaser interaction provides a simulation which describes the main steps and effects of process.

\section{CONCLUSIONS}

A thermomechanical finite element model has been developed to simulate the laser innovative rapid prototyping process. The mechanical model takes into account the phase change, material injection and surface tension at liquid state. The coupling with thermal model takes into account fusion and vaporisation effects. The thermomechanical model is completed by coupling with material-laser interaction. The laser is considered as a surface heat source. And interaction effects are modelled by absorptivity of material, plasma absorption and temperature.

This numerical model has been implemented in order to calibrate and optimize the process that is, at the moment, under development and validation.

\section{ACKNOWLEDGEMENT}

We acknowledge the support of the CLAIRE center in this project, as well as the Provence Alpes Cote d'Azur regional council for its financial support.

\section{REFERENCES}

[1] Forestier R.: Finite element thermomechanical simulation of steel continuous casting. TMS (The Minerals Metals \& Materials Society), 2009.

[2] Cerri O.: Hot tearing in steels during solidification: experimental characterization and thermomechanical modelling. Journal of Engineering Materials and Technology, vol. 130, 2008.

[3] Costes F., Modélisation thermomécanique tridimensionnelle par éléments finis de la coulée continue d'aciers, Mines Paristech thesis, 2004.

[4] Hysing S., A new implicit surface tension implementation for interfacial flows, Numerical methods engineering, 51: 659-672, 2006.

[5] Bansch E., Finite element discretization of the Navier-Stokes equations with a free capillary surface, Numerical mathematics, 88: 203-235, 2001.

[6] Zhou J.: Modelling of transport phenomena in hybrid laser-MIG keyhole welding, International Journal of Heat and Mass Transfer, 51: 4353-4366, 2008.

[7] Debroy T., Physical processes in fusion welding, Reviews of Modern Physics, 67:85-112, 1995.

[8] Hermann J., Caractérisation de plasma crée lors de l'intéraction laser cible métallique, Orléans University thesis, 1991. 